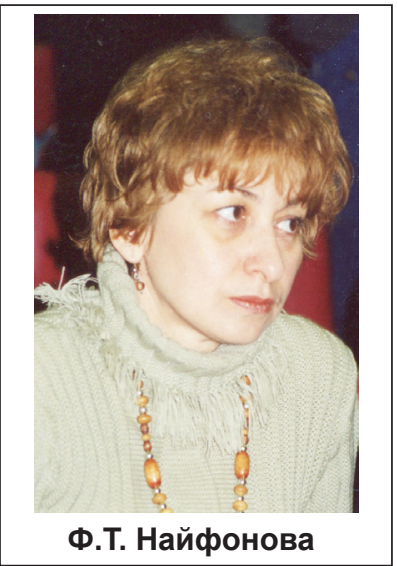

УДК 39

\title{
СТАТЬЯ Б.У. ЧЕРДЖИЕВА «КОЕ-ЧТО О ЧЕРЕПНОЙ ХИРУРГИИ ДРЕВНИХ ОСЕТИН»
}

\author{
Ф.Т. Найфонова*
}

Борис Умарович Черджиев (1937-2004) - уроженец селения Дзуарикау, в 1956 году поступил в Северо-Осетинский государственный педагогический институт им. К.Л. Хетагурова, который успешно закончил в 1960 по специализации "ффизическое воспитание, анатомия и физиология человека». С момента окончания института Борис Умарович посвятил жизнь педагогике. С 1970 года он вел курс физвоспитания в Горно-металлургическом техникуме, и за годы своего учительства приобщил к физической культуре, спорту и здоровому образу жизни не одно поколение молодежи.

Несмотря на то, что Черджиев не был профрессиональным историком, он проявлял живой интерес к осетинской традиции, этнографрии, истории, и великолепно писал как на осетинском, так и на русском языке. Он собирал осетинские поговорки и пословицы, многие из которых записывал со слов старших, фиксировал сведения по этнографрии осетин. Основные записи Бориса Умаровича были сделаны в 60-х годах прошлого столетия. Они не были введены в научный оборот и остались за порогом внимания исследователей. Надеемся, что статья, которая при его жизни не была опубликована (она датирована 12 феераля 1995 г.), заслуживает внимания современного читателя. Она не является в строгом смысле научным исследованием, но представляет интерес как с точки зрения медицины, так и с точки зрения этнографрии. Ее достоинство заключается в нетривиальном взгляде и правильной расстановке акцентов в столь сложной и неоднозначной теме, корни которой уходят в глубину веков.

Здесь ставится проблема сохранения традиций народной медицины, обосновывается положение о существовании приемов древней трепанации черепа у предков современных осетин, описываются методы народного иелительства, которые еще в 60-х годах XX столетия успешно использовали в Осетии народные целители - Арсамаг Цопанов, Гайши Кудзиев и Фаризат Дзодзикова, непосредственно от которых автор и записал некоторые процедуры. Борис Черджиев отмечает недостаток палеоантропологического материала для подтверждения версии о существовании у осетин древней черепной хирургии. Но он удачно компенсирует это данными языка, фольклора и Нартского эпоса (хотя в этой части мы позволили себе сократить материал).

\section{КОЕ-ЧТО О ЧЕРЕПНОЙ ХИРУРГИИ ДРЕВНИХ ОСЕТИН}

\section{Б.У. Черджиев}

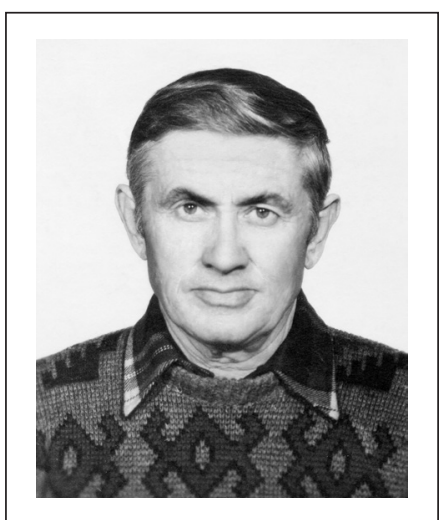

Осетия. Методы и приемы эти нигде не фиксируются. С каждым годом все меньше и меньше становится знатоков народной медицины; это значит, что мы безвозвратно теряем способы и приемы народной медицины, а ведь они дошли до нас из глубокой старины, это частица нашей истории. Недавно, читая книгу Д.Г. Рох-

Трудно, интересно и полезно собирать и фриксировать приемы народной медицины, знатоками которых так богата Северная

Как организм может привыкнуть к действию яда, так и человеческая мысль сродняется с устарельми заблуждениями.

Джордано Бруно . *Найсронова Фатима Тасолтановна - член Союза журналистов РФ, библиографр (n.fati@mail.ru). Абаев В.И. Осетинский язык и фольклор. - М.-Л.: Издательство АН СССР, 1949. С. 597. лина «Болезни древних людей» [2], я спросил себя: а чем же болели древние осетины и как они лечились?

По этому поводу у В.А. Абаева читаем: «Известно, что древнейшее лечение включало два главнейших элемента: колдовство и травы. Они применялись либо раздельно, либо в комбинации друг с другом. Позднее к ним присоединилось еще третье средство: нож первобытного хирурга» ${ }^{1}$. О первобытном хирурге из предков современных осетин и пойдет речь.

В книге Мейер-Штейнега и Зудгофра «История медицины» читаем: «Заслуживает внимания одно хирургическое вмешательство, которое 
практикуется многими дикими народами и которое, как показывают многочисленные костные находки, было известно первобытному человеку. Речь идет о трепанации черепа, которая производилась отчасти путем просверливания кости, отчасти постепенного соскабливания ее; для того, чтобы болезнь легче могла выйти из больного, первобытные люди делали на черепах маленьких детей трепанационные отверстия» ${ }^{2}$.

В настоящее время науке известно более двухсот черепов с отверстиями, которые истолковываются как следы искусственных трепанаций [3]. Искусственную трепанацию черепа наука рассматривает как хирургию древних людей.

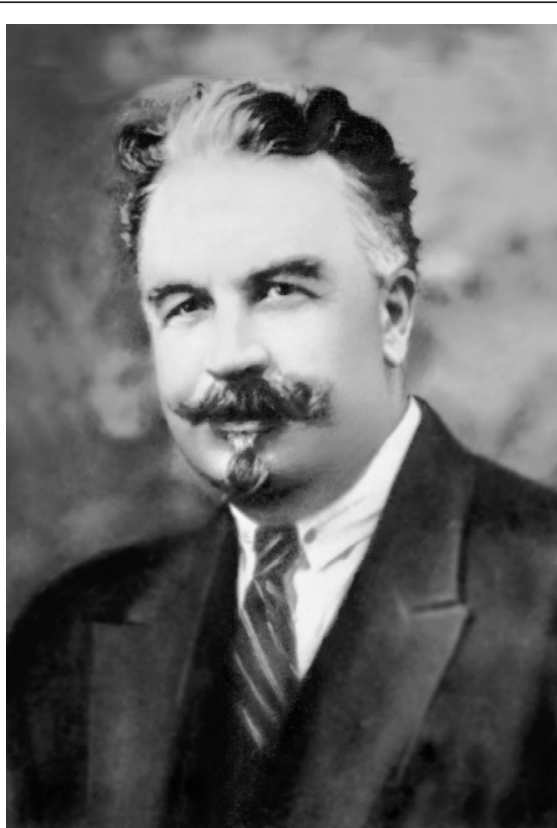

М.А. Мисиков древним хирургом. Но вдруг М. Домба делает поворот на сто восемьдесят градусов и заявляет, основываясь на патологоанатомических наблюдениях, что круглые пробоины на доисторических черепах являются следами смертельных ран в бою, при жертвоприношении, при погребении жены или раба вместе с умершим господином, или же на каннибальском пиршестве [6]. «Во всех этих случаях нарушения целостности костей черепного свода не могут быть названы трепанационными и не имеют никакого отношения к черепной хирургии, существование которой в доисторические эпохи никем научно не доказаHO॥ ${ }^{4}$.

В течение целого столетия, Да, все это так, но из этих двухсот черепов, известных науке, ни один череп не имеет ни малейшего отношения к предкам современных осетин.

Отсутствие археологического материала по данному вопросу максимально затрудняет решение вопроса, и вдруг, как говорят, Бог дает, в окно подает. Мне стало известно, что в 1936 году профрессор М.А. Мисиков [4] в Верхнем Кобане на склоне горы Харзет (Хурызад) с полутораметровой глубины извлек два черепа: мужской и женский. Для антропологического изучения и описания М.А. Мисиков передал их Моисею Григорьевичу Домба [5], читавшему тогда курс описательной анатомии в Северо-Кавказском педагогическом институте.

Особое внимание исследователя привлек мужской череп с огромным отверстием в черепном своде (3,3 x 2,4 см). После тщательного изучения мужского черепа из кобанского некрополя М. Домба пришел к выводу, что субъект был очень крепкого телосложения. И далее пишет насчет отверстия в теменной области: «Оно представляет собою след прижизненного ранения, было получено, несомненно, задолго до смерти субъекта, так как громадная площадь регенерации (восстановленной) кости требует большой регенеративной способности организма, чего нельзя предположить у глубокого старика» ${ }^{3}$.

Стало быть, мы имеем дело с мужским черепом из кобанского некрополя, обработанным начиная со второй половины XIX века, дискуссируется вопрос о трепанационных отверстиях, обнаруженных на некотором числе черепов людей, живших в эпоху неолита, бронзы и железа. Дискуссируется в основном археологический материал (Дебец Г.Ф., Дранцын А.А., Крупнов Е.И., Лункевич В.В., Уварова П.С., Уваров А.С., Майер, Поль Брок, Вирхов, Мейер-Штейнег и др.). К сожалению, палеопатологический анализ остатков древних осетин пока что вынужден довольствоваться наблюдениями единичных объектов за неимением материала. Зато этот пробел блестяще дополняет языковой материал, фольклор, Нартский эпос. Каждое слово-понятие, если удастся раскрыть его историческое содержание, представляет ценнейший документ, по древности своей конкурирующий с древнейшими памятниками материальной культуры ${ }^{5}$.

Если бы уважаемый М. Домба хоть издалека посмотрел на Нартский эпос, он бы сразу заметил, что тот изобилует съемными сводами черепов [7]. Достаточно, например, вспомнить отрывок из сказания о «Безымянном сыне Урузмага». Медь у нартов шла на котлы, а также служила, по свидетельству некоторых сказаний, для починки в небесной кузнице Курдалагона разбитых в бою черепов [8]. А у Сека Гадиева в рассказе «Куртатинский лгун» главный герой в своем съемном черепном своде жарит яичницу из перепелиных яиц. 
Конечно, все это ни что иное, как всего лишь образное, художественное отражение искусственной трепанации, черепной хирургии и психотерапии древних осетин в фольклоре и эпосе. Но в 1960 году мне посчастливилось зафиксировать некоторые сведения об этом явлении со слов знаменитого костоправа Цопанова Арсамага и знатока приемов трепанации черепа Кудзиева Гайши, жителей селения Дзуарикау, и Дзодзиковой Фаризат (Дзадзи) из селения Суадаг (из них никого уже нет в живых).

Больному-эпилептику (хæйрæджджын, æрра, суртæ2æнæ2) брили голову, мыли ее холодной водой, вытирали насухо, а потом на черепномозговую часть накладывали тонкий слой из теста (сæры хыссæ) и наблюдали за тем, на каком участке начинает высыхать тесто. Это повторялось до тех пор, пока не устанавливали одну и ту же зону, где тесто высыхало раньше, нежели на других участках - место беса (хæйрæджы бынат). После этого удаляли тесто (сæры хыссæ), но не выбрасывали. Оно шло на изготовление специальных пирогов.

Затем брали специальный инструмент «сасари» (род ланцета), накладывали на то место, где тесто высыхало, и ударяли по «сасари» кулаком. В результате кожа и мясо разрезались на мелкие квадраты, после чего удалялись специальным скребком (сыкъафистонджын кард) - нож с костяной рукояткой, потом тем же ножом или кинжалом отца, брата или близкого родственника соскабливали кость до самого мозга. Во время этой процедуры больному вместо воды давали рассол (суардон).

Руки скручивали больному за спину так, что голова уходила между ног [9]. Все это время не переставали повторять больному на ухо: «Дæ хæйрæджы ном зæ2ъ, кæм иæры дæ хæйрæ2, цы хуыйны дæ хæйрæ2» («скажи имя твоего беса, где живет твой бес, как зовут твоего беса»). Видимо, отсюда и пошло предостережение: «Уыдон дын дæ хæйрæджы ном зæ2ъын кæндзысты» («они заставят тебя назвать имя твоего беса»). Или выражение: «Мæ кард сасарийы хуызæн» («мой нож остер, как сасари»).

А при головных болях в результате ушиба или удара головы Фаризат Дзодзикова пользовалась приемами мануальной терапии, и не без успеха, а свой диагноз называла «хуыдиртæст» - букв. «разошедшиеся швы», где «хуыд» - шов, «иртæст» - «разошедшийся, отделенный».

К сожалению, я не зафиксировал, как назывались у осетин другие хирургические инструменты для проделывания трепанационных отверстий. Зато язык четко и ясно зафиксировал черепную хирургию в виде искусственной трепанации и как психотерапию.

В современном осетинском языке больного эпилепсией одинаково обозначают двумя словами - «хæйрæджджын» (бесноватый) и «сæрхъæн»(с поврежденной головой). Для предков же осетин было небезразлично, каким именно словом обозначать эпилептика. Видимо, до нарушения целостности костей черепного свода психически больного называли «хæйрæджджын», а после трепанации о нем говорили: «сæрхъæн». Однако это было не всегда так. У осетин человека, имевшего значительные повреждения целостности костей черепного свода, но с нормальной психикой, никогда не обозначали словом «сæрхъæн».

Вероятно, неоднократная трепанация одного субъекта обозначалась и словом «сæлхæр» из «сæрхæлд» - букв. «испорченная голова», где

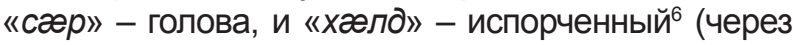
осетинское посредство «сæлхæр» проникло в балкарский и сванские языки с тем же значением ${ }^{7}$ ).

Здесь, вероятно, уместно упомянуть еще об одной процедуре, именно «сæрæвæрд» - «установление головы», «придание голове определенной формы». По сообщению Фаризат Дзодзиковой, перед первым укладыванием ребенка в люльку «сæр æвæрдтой» - ставили голову, т. е. по несколько раз сжимали голову ребенка между ладонями в переднезаднем направлении со словами: «Дур дурæй хъæбæрдæр» (камень камня крепче). Известно, что обычай искусственной деформации костей черепа существовал у алан в IV-VI веках.

Для чего наши предки прибегали к трепанации?

1. При травматической эпилепсии удалялись костные осколки.

${ }_{6}^{6}$ Абаев В.И. Историко-этимологический словарь осетинского языка: в 4 т. - М.-Л., 1958-1989. Т. 3. С. 85.

Абаев В.И. Осетинский язык и фольклор. - М.-Л., 1949. С. 238-300. 
2. Разъединялись сросшиеся участки коры головного мозга с костной тканью.

3. Декомпрессировалось внутричерепное давление (методом внушения изгонялись злые духи, демоны, бесы).

В итоге нормализировалось кровоснабжение коры головного мозга и, как следствие, состояние больного улучшалось. Правда, не всегда наши предки сразу достигали ожидаемого результата. В этом случае, как было уже сказано, проводили повторную трепанацию.

На наш взгляд, даже самое общее знакомство с осетинской духовной культурой и историей народной осетинской медицины исключает всякое сомнение о существовании трепанации черепа у предков осетин.

\section{ПРИМЕЧАНИЯ}

[1] Возможно, статью было бы корректней озаглавить «К вопросу о черепной хирургии в традиционной медицине осетин», - однако мы сохраняем название источника. [2] См. Рохлин Д.Г. Болезни древних людей. - М.-Л.: Наука 1965.

[3] На текущий момент коллекция подобных черепов значительно увеличилась - в нескольких регионах Северного Кавказа были обнаружены древние черепа со следами трепанации. Находки датируются V-III mыс. до н. э. Российские и немецкие ученные, исследовавшие культуру бронзового века и эти черепа, обратили внимание, что после трепанации доисторические люди выживали, а отверстие в черепе проделывалось в одном и том же месте - посредине затылка, как и в нашем кобанском черепе.

[4] Магомет Асланикоевич Мисиков (1881-1938) был первым осетинским антропологом, научные труды которого не потеряли своей значимости по сей день. Профессор использовал в работе передовые для своего времени достижения европейской научной мысли в области антропологии, - как, например, в статье «Сравнительные изме рения черепов у разных народов», опубликованной в 1926 году в "Известиях Горского Педагогического Института». A его работа "Этнографические исследования об осетинах» (Владикавказ: арвАсин, 2011. - 157 с.) стала иенным вкладом в осетинскую этнографию. Однако М.А. Мисикова постигла трагическая участь: на взлете своей научной и активной общественной деятельности, в 1938 году он был репрессирован, а его имя на долгие годы оказалось под запретом.

[5] М.Г. Домба, врач-невропатолог, перу которого принадлежит работа "Учение о микроцефралии в филогенети ческом аспекте» (Орджоникидзе, 1935), больше известен в Осетии под литературным псевдонимом Мусса Хаким, под которым, в частности, издал книгу «Махарбек Туганов - народный художник Осетии» (Орджоникидзе, 1962). См.: Хугаев И.С. Мусса Хаким (М.Г. Домба) и его письма к Хаджи-Мурату Мугуеву // Известия СОИГСИ, вып. 21 (60) 2016. C. 142-165. URL: http://izvestia-soigsi.ru/ru/archive/-2160-2016/450-hugaev (дата обращения: 18.02.17)

[6] М.Г. Домба даже определяет орудие, которым оно было нанесено: «Возникает вопрос, - рассуждает он, - каким же орудием нанесены раны, следы которых остались на мужском кобанском черепе. Из оружейного инвентаря кобан ских могил только топор можно считать предполагаемым орудием для нанесения раны» (Домба М.Г. Указ.соч. С. 71). В качестве примера М.Г. Домба приводит обзор предметов кобанской бронзы, где в большом количестве фригурируют знаменитые кобанские топорики. При этом из поля зрения Моисея Домба почему-то выпали медицинские инструменты кобанцев - бронзовые ножи, предшественники современного орудия хирурга - скальпели и пинцеты, описанные известным ученым-археологом БагратомТеховым (См.: Техов Б.В. "Археология южной части Осетии». Монография - Владикавказ: Ир, 2006. с. 287, с. 279). Невольно возникает вопрос, почему Магомет Мисиков - ученый в области антропологии, не занялся изучением кобанского черепа сам, а передал его Моисею Домба. К сожалению, ответа нет. Возможно лишь предположить, что профрессор, державший в руках множество черепов, имел представление об уникальном значении своей находки. Однако результаты анализа Домба свели ее на нет.

[7] Не вполне справедливый упрек: М.Г. Домба был знатоком осетинского фольклора; его перу принадлежат даже переводы на русский язык некоторых Нартских сказаний.

[8] В наши дни к этой теме обратились и осетинские ученые Е.Б. Бесолова и Л.Б. Моргоева в статье «Об элементах народной медицины в сказаниях Нартовского эпоса», где они задались иелью «на материале Нартовских сказаний выявить устойчивые элементы традиционной медицины, и через их освещение попытаться проникнуть в тайны ее зарождения. Как явствует из сказаний, народные знахари и костоправы умели лечить и воскрешать умерших, латать черепа... В сказании о том, как Сослан добывает себе жену, повествуется: Сослан ударом меча отсекает убегающему врагу, сыну Хиза, Челахсартагу (или Сайнаг-Алдару), половину черепа. Небесный кузнеи Курдалагон накладывает ему на череп заплату из медной пластины. Здесь, на наш взгляд, приводится свидетельство «трепанации» черепа в древности. Эпоха бронзы и раннего железа обогатила человечество, подарив медицине металлические инструменты» (Бесолова Е.Б., Моргоева Л.Б. Об элементах народной медицины в сказаниях нартовского эпоса // Современные проблемы науки и образования. - 2015. № 2-3.

URL:https://science-education.ru/ru/article/view?id=23706 (дата обращения: 21.02.2017).

[9] Не слишком наглядное описание положения пациента; вероятно, автор упустил какую-то деталь.

\section{ARTICLE BY B.U. CHERDZHIEV «ON CRANIAL SURGERY OF THE ANCIENT OSSETIANS» \\ F.T. Naifonova \\ Member of the Russian Union of Journalists, bibliographer (n.fati@mail.ru).}

